\title{
Guest Editorial: Special Issue on THz Radiation Applied to Cultural Heritage
}

\author{
Gian Piero Gallerano ${ }^{1} \cdot$ Kaori Fukunaga ${ }^{2}$. \\ Marcello Picollo ${ }^{3}$
}

Received: 29 January 2017 / Accepted: 31 January 2017 /

Published online: 10 February 2017

(C) Springer Science+Business Media New York 2017

It has just been over 10 years since Terahertz radiation was applied to art conservation studies for the first time. The unique potential and the development of $\mathrm{THz}$ radiation applications in this research field are based on the radiation capability to penetrate the different layers of paintings, frescoes, mosaics, and archaeological objects depending on the specific frequency used, in order to provide information about their morphological, physical, and chemical properties. Following the early investigations on mock-up samples and proof-of-principle experiments, over the years, $\mathrm{THz}$ imaging and spectroscopic techniques have gradually complemented the existing X-ray, visible and infrared (VIS/IR) spectroscopic and imaging technologies in the effort to provide powerful, non-invasive, multi-frequency analysis tools to researchers working in the field of cultural heritage conservation.

This special issue of the Journal of Infrared Millimeter and Terahertz Waves collects a selection of invited papers that provide the state-of-the-art of the applications of mm-waves and $\mathrm{THz}$ radiation in art conservation studies. With an impressive variety of case studies, the papers cover a wide range of subjects, from paintings (easel, panel, mural paintings), to lacquerware and sigillography, as well as from manuscripts deciphering, to image analysis and information retrieval algorithms.

The paper "Art painting diagnostic before restoration with terahertz and millimeter waves" addresses the study of a painting of the seventeenth century that was investigated using both time domain imaging (TDI) and a frequency modulated continuous wave (FMCW) system in the millimeter frequency range. This study underlines the differences and relative advantages/ disadvantages between FMCW and TDI.

Gian Piero Gallerano

gianpiero.gallerano@enea.it

1 ENEA, FSN - Fusion Physics Division, 00044 Frascati, Italy

2 National Institute of Information and Communications Technology, Tokyo 184-8795, Japan

3 IFAC-CNR, 50019 Sesto Fiorentino, Italy 
Two different types of mural paintings are studied in the papers: "Investigation of layer structure of the Takamatsuzuka mural paintings by Terahertz Imaging Technique", which is related to one of the most important Japanese work of art, and "Terahertz and hyperspectral investigations on a fresco-painting on "tavella" by Alessandro Gherardini", respectively. For this latter artwork, hyper-spectral imaging measurements in the 400-1700 nm range are also reported, which made possible to determine the state-of-conservation of the Gherardini's painting, while the reflection imaging measurements performed in the millimeter wave range provided a qualitative evaluation of the position of defects inside the "tavella".

Easel and panel paintings investigations are covered by the two papers "History of Mexican Easel Paintings from an Altarpiece Revealed by Non-invasive Terahertz Time-Domain Imaging" and "Insights on the side panels of the Franciscan Triptych by Fra Angelico using Terahertz timedomain imaging (THz-TDI)" respectively. Both studies compared the results of THz-TDI with standard imaging techniques, such as for instance X-ray radiography. By combining the records of the paintings obtained by imaging with the different methodologies, aspects of the original paint layers and further details on the easel paintings' history were revealed, in which THz-TDI played a key role in attributing a chronological evolution of the paintings. In the case of the Franciscan Triptych by Fra Angelico, THz analysis supplied information on its stratigraphy and the associated construction, "gessoing" and gilding techniques. Furthermore, THz-TDI provided information on the extension and nature of subsurface fractures.

Lacquerware investigations are addressed in the paper "Inspection of Asian lacquer Substructures by Terahertz Time-Domain Imaging (THz-TDI)". Since lacquerwares are mostly composed of organic materials, standard X-ray radiography does not provide sufficient contrast in the acquired images. Three different kinds of Asian lacquerwares were examined by THz-TDI, and the outcomes were compared with those obtained by standard X-ray radiography. As a result, THz-TDI demonstrated the capability to provide unique information on lacquerwares substructures.

Non-invasive diagnostics of ancient manuscripts is covered in the three papers: "Confocal Terahertz Imaging of Ancient Manuscripts", "Contrast in terahertz images of archival documents - Part I: Influence of the optical parameters from the ink and support" and "Contrast in terahertz images of archival documents - Part II: Influence of topographic features".

Two further papers, "2D and 3D Terahertz imaging and X-Rays CT for sigillography study" and "Non-destructive analysis of material detachments from polychromatically glazed terracotta artwork by THz time-of-flight spectroscopy" respectively, show how THz imaging and spectroscopy can be usefully applied to the study of 3D non-flat objects.

Finally, the paper "A filtering procedure for $\mathrm{THz}$ imaging: performance assessment on art work specimens" addresses a method of image processing aimed at reducing noise, filtering out undesired signal introduced by measurement system and performing surface topography correction. The usefulness of the proposed data processing chain was assessed both by using data collected on a mock-up sample and an ancient mortar specimen decorated with colored stucco.

We sincerely thank the Editor-in-Chief of JIMT, Prof. Martin Koch, for his support and encouragement in setting up this special issue. We also wish to thank the reviewers who have contributed in selecting the papers and improving their quality. We hope that this special issue will attract more readers to the Journal and will stimulate further studies in the exciting field of non-invasive diagnostics of cultural heritage.

Gian Piero Gallerano, Kaori Fukunaga, Marcello Picollo

Guest Co-Editors 